\title{
Incident cervical infections with high- and low- risk human papillomavirus (HPV) infections among mothers in the prospective Finnish Family HPV Study
}

\author{
Karolina Louvanto ${ }^{1,2^{*}}$, Marjut A Rintala², Kari J Syrjänen ${ }^{3}$ Seija E Grénman² and Stina M Syrjänen ${ }^{1}$
}

\begin{abstract}
Background: The knowledge on type specificity and factors that increase or decrease the risk of incident HPVinfections is important to better understand the dynamics of HPV-infections.

Methods: A series of 329 pregnant women were enrolled in Finnish Family HPV Study at $3^{\text {rd }}$ trimester of pregnancy and followed-up for 6 years, during which 203 baseline HPV-negative women acquired incident HPV infection. Incidence times and incidence rates (IR) were calculated for 24 low-and high-risk HPV-types detected by Multiplex-HPV-genotyping at each visit. Poison regression was used to estimate predictors of incident HPV infections of species 7 and 9 HPV-genotypes.
\end{abstract}

Results: HPV16 was the most frequent (47.8\%) incident genotype followed by multiple-type infections (25.1\%), and single infection with HPV18, 70,6 and 45. Actuarial mean times to incident event were longest for HPV31 (34.5 months) and HPV45 (32.8 months), while crude mean times were longest for HPV56 (42.4 months) and HPV16 (23.1 months). Actuarial IR was highest for HPV16 and multiple-type infections. Independent protective factors against incident infections were 1) $>2$ life-time sexual partners $(p=0.014), 2$ ) later initiation of oral contraceptives (age $>$ 20 years) ( $p=0.017)$ and 3$)$ pregnancy at FU visit $(p=0.0001)$.

Conclusions: Among newly delivered mothers, higher number of life-time sexual partners, initiation of OC use after age 20 and becoming pregnant during FU decreased the risk for incident species 7/9 HPV infections.

\section{Background}

Human papillomavirus (HPV)-types that infect the female genital tract belong to the alpha-papillomavirus-genus which includes 15 species and 58 HPV-genotypes. According to their clinical behavior, 15 HPV-types are high-risk (HR)-types, 12 are low-risks (LR)-HPV-types, and three probable HR-types [1,2]. Worldwide, the eight most common HPV-types in cervical cancer are all included either into species7 (HPV18,45) or 9 (HPV16,31,33,35,52,58) [3]. The studies on incident HPV-infections have been evaluating HR- and LR-types collectively or HPV in general [4-7]

\footnotetext{
* Correspondence: karolina.louvanto@utu.fi

'Medicity Research Laboratory and Department of Oral Pathology, Institute of Dentistry, Faculty of Medicine, University of Turku, Lemminkäisenkatu 2, 20520 Turku, Finland

Full list of author information is available at the end of the article
}

or acquisition of incident HPV-infections have been assessed at genotype level [8-16].

Among young women, incident infections with HRHPV-types especially with HPV16 [8-11,14-16] seem to be more common than LR-types $[9,17]$. The knowledge on type specificity and factors that increase or decrease the risk of incident HPV-infections is important to better understand the dynamics of HPV-infections and to take appropriate measures for their optimal prevention.

The aim of this study was to assess the frequency of type-specific incident HPV-infections in addition to actuarial and crude incidence-times and -rates of the most common LR- and HR-HPV- genotypes in newly delivered mothers, prospectively followed-up for 6 years in the Finnish Family HPV Study. Risk-factors of incident

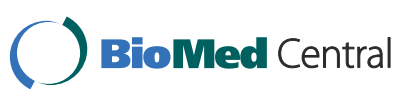


HPV-infection were analyzed with univariate and multivariate Poisson regression for panel data.

\section{Methods \\ Subjects}

The Finnish Family HPV Study is a prospective cohort study conducted at the Department of Obstetrics and Gynecology, Turku University Hospital and the Institute of Dentistry, Faculty of Medicine, University of Turku. The study was designed to evaluate the dynamics of HPV infections in mothers, fathers and their newborn infants. A total of 329 women, 131 men and 331 children were recruited to this study between 1998 and 2002. An extended 6 years follow-up was performed between 2006 and 2008, and invitation to this follow-up visit was send to all women and men in this cohort; a total of 171 women and 44 men was finally reached and examined.

Subjects in this cohort comprise mothers-to-be who were recruited at the minimum of 36 weeks of pregnancy [18] and followed-up for up to 6 years $($ Mean $=54.9$ months, $\mathrm{SD}=27.3$, Median $=62.4$; range: $1.6-94.5$ months) after the delivery. The Research Ethics Committee of Turku University Central Hospital has approved the study protocol and its amendment (\#2/1998 and \#2/2006) and an informed consent have been gained from all the participants of this study. Altogether, 329 mothers were recruited (mean age 25.5 years, $\mathrm{SD}=3.6$ years), of whom 203 baseline HPV-negative women (mean age 25.48 years, $\mathrm{SD}=3.1$ years, range 18-38) who developed an incident event during the follow-up (FU) were included in this study. The women of this study are of Caucasian origin, have the same ethnic background and are representative of the Finnish population. The flowchart of the study setting is described in Figure 1. Some of the study participants were lost to follow-up, mainly due to difficulties in getting to study appointments or lack of child care. Structured questionnaire for recording demographic data and potential risk factors (i.e. sexual behavior, gynecological and obstetric history and risk factors for HPV infections) were recorded at the 2-month and 6-year FU-visits. During the 12-month and 36-month FU-visit, the data on the presence of HPV-induced clinical lesions, such as oral papilloma, skin and genital warts were recorded. Selected data from these records were used for risk assessment in the present study, as separately indicated.

\section{Samples}

The scrapings for HPV-testing were taken at the baseline and at 2-,12-,24-,36-month and 6-year FU-visits. Sampling was done with a cytobrush from the uterine cervix (Cytobrush, MedScand, Malmö, Sweden) using sampling media of $0.05 \mathrm{M}$ phosphate-buffered saline with $100 \mu \mathrm{g}$ gentamycin. The samples were immediately frozen at $-20^{\circ} \mathrm{C}$ and stored at $-70^{\circ} \mathrm{C}$. Scrapings from the

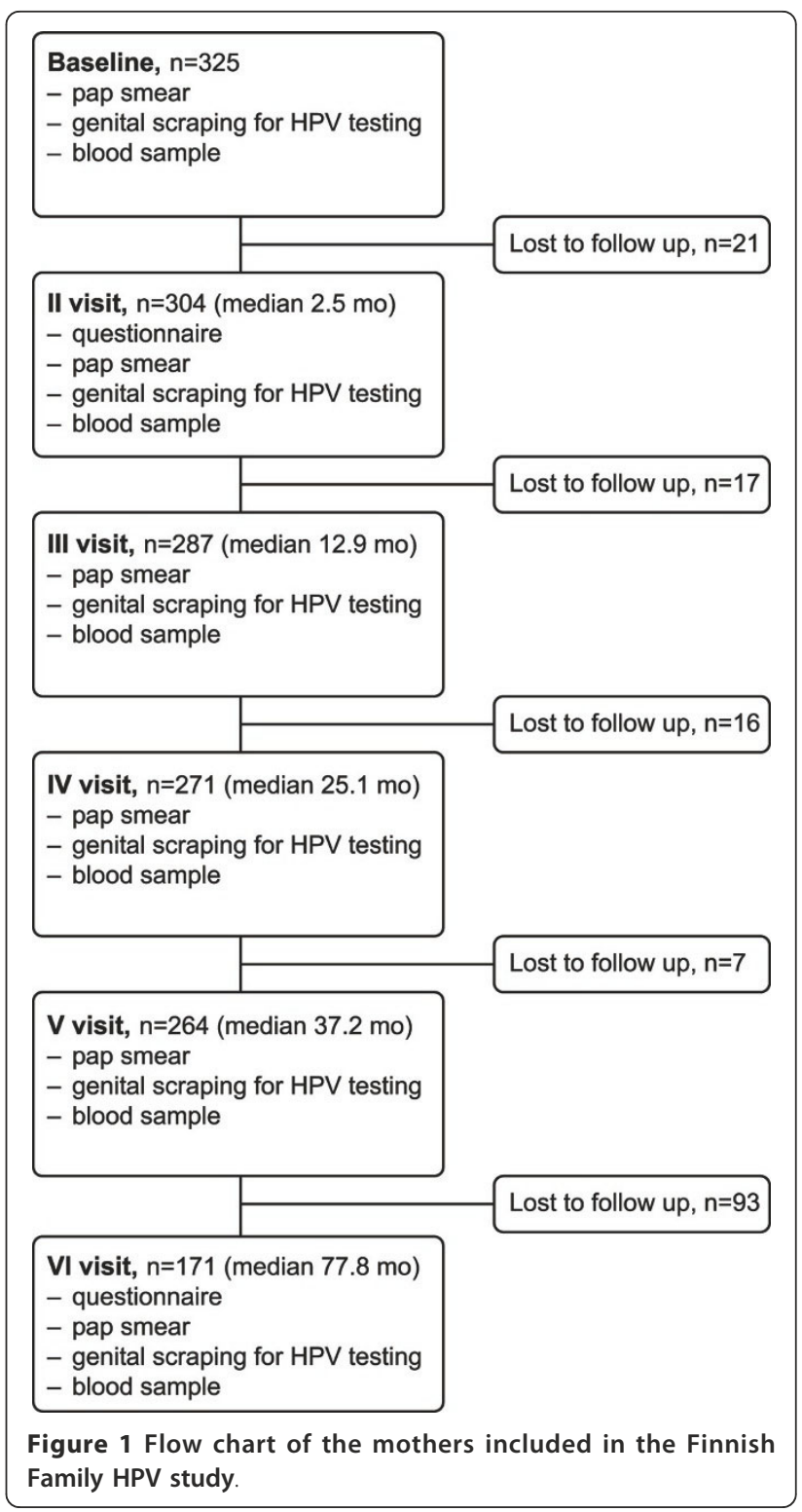

oral mucosa were also collected at each visit [19], but only the baseline DNA data were used in the present study.

\section{Pap smears}

A routine pap smear was taken from all women at baseline, and 2-,12-,24- and 36-month, by using conventional three-sample technique with wooden spatula and cytobrush (Medscand, Malmö, Sweden) as described earlier [18].

\section{HPV-genotyping}

The HPV genotyping was done by multiplex-HPV-genotyping kit (Multimetrix, Progen Biotechnik GmbH, Heidelberg, Germany) as outlined in our recent study [20]. 
The kit identifies the following 24 LR- and HR-HPVgenotypes: LR-HPV: 6,11,42,43,44,70; HR-HPV: 16,18,26, $31,33,35,39,45,51,52,53,56,58,59,66,68,73,82$ [21]. With Luminex LX-100-analyzer (Bio-Plex 200 System, BioRad Laboratories, Hercules, USA) medium fluorescence intensity (MFI) of at least 100 beads was computed for each bead set in the sample. The cut-off value for each run and HPV-type was 1,5x background MFI (negative control) $+5 \mathrm{MFI}$.

HPV genotyping was done using the earlier PCR product which was now re-amplified with GP05+ and bioGP06+-primers [22]. Originally DNA was extracted from scrapings with high salt method [23]. The PCR products were then hybridized with digoxigenin-labelled HR-HPV oligoprobe cocktail (HPV-types 16,18,31, $33,35,39,45,51,52,54,56$ and 58) to detect the presence of any high risk HPVs [24].

As HPV16 is the most prevalent genotype, we retested all HPV16-positive samples as described by Schmidt and co-workers [21] and discounted the possibility of false positive samples due to contamination.

\section{Serology}

Blood samples were taken at baseline and at 2-,12-,24and 36-month and 6 years of FU. Samples were analysed for the antibodies to the major capsid protein L1 of HPV types 6,11,16,18 and 45, and were analysed by multiplex HPV serology based on glutathione S-transferase fusion-protein capture on fluorescent beads. These results were interpreted using the technique and cut-off values as recently described [25]. The Selected data from these records were used for risk assessment in the present study (Table 1).

\section{Statistical analyses}

All statistical analyses were run using SPSS $^{\circledR}$ (SPSS, Inc., Chicago, USA) and STATA (Stata Corp., College Station, TX, USA) software packages (PASW Statistics for Windows, version 18.0.1 and STATA/SE 11.0). Frequency tables were analyzed using the $\chi^{2}$-test, with the likelihood ratio or Fisher's exact test for categorical variables. Differences in the means of continuous variables were analyzed using non-parametric (Mann-Whitney or Kruskal-Wallis) tests for two- and multiple independent samples, respectively.

\section{Outcomes of HPV-infection and type-specific incident infection}

The genotype-specific outcomes in each woman were assessed by comparing the viral events at each FU visit to the baseline HPV status and are presented in Figure 2. The following 6 different outcome patterns were defined: 1)always negative, 2)incident HPV, 3)type-specific persistence, 4)non type-specific persistence, 5)fluctuation, and 6) clearance (= transient). The present study focused on those 203 baseline-negative women who developed an incident HPV-infection during the FU (outcome 2) (= women who were HPV-negative at baseline and acquired incident HPV infection during the FU). Genotype-specific persistence denoted for any case with two (or more) consecutive FU-samples positive for the same individual genotype as a single infection or as a part of multiple-type infection. Non-genotype specific persistence includes all cases with two (or more) consecutive samples positive for different HPV genotypes. Clearance was defined as an event (at any FU visit) when a previously HPV-positive test turned out to be negative and remained HPV-negative until the end the FU. Fluctuation is a pattern where consecutive samples are intermittently HPV+ and HPV- with different HPV genotypes, without any two consecutive samples positive for the same or different viral genotype.

Times in months to incident infections were calculated from baseline visit to the first incident event separately for actuarial and crude times. To calculate the former, all baseline HPV-negative women $(\mathrm{n}=255)$ were included in Kaplan-Meier analysis, cases being censored at the first incident event (those who had) or at the end of FU (those who did not develop incident event). Only those women who had completed at least two FU visits were included to this study. To calculate the crude incidence times, only those women with an incident infection with an individual genotype (or species) were included. Both actuarial and crude incidence rates (IR) were calculated, and expressed per 1000 women months at risk (wmr). To get genotypespecific actuarial IRs, the number of incident events for each individual genotypes (and species) was divided by the total wmr $(6,212$ months for all baseline HPV-negative women), including also the women with no incident event. To calculate crude IRs, only the women with incident events were included and the number of incident events for each individual genotype (or species) was divided by the wmr of those women only. To compare the individual IRs, the rate ratio statistics (STATA) was used, with testspecific 95\% confidence intervals (95\%CI).

\section{Predictors of type-specific incident HPV-infections}

To analyze the predictors of incident HPV-infections, we used the species-specific incident infection approach to avoid stratifying the material into individual genotypes with single or few cases only. Furthermore, we were only interested in incident HPV-infections by the key HR-HPV-types, i.e., those of Species 7 and Species 9. Women that had an incident infection recorded by a type or types from species 7 and/or 9 were included to these analyses $(n=133)$.

Poisson regression analysis was used for panel data, clustered by mother-ID and executed (in univariate and multivariate-mode) using population-averaged (PA) 
Table 1 Predictors of species 7 and 9-type specific incident ${ }^{a}$ HPV infections $^{b}$

\begin{tabular}{|c|c|c|c|c|c|c|}
\hline \multirow[t]{2}{*}{ Covariates } & \multicolumn{6}{|c|}{ Incident Species 7 and 9 HPV Infections } \\
\hline & Crude IRR & $95 \% \mathrm{Cl}$ & $P$ & @Adjusted IRR & $95 \% \mathrm{Cl}$ & $\mathbf{P}$ \\
\hline Age (at study entry; continuous var) & 0.98 & $0.96-1.02$ & 0.090 & 0.99 & $0.98-1.01$ & 0.678 \\
\hline \multicolumn{7}{|l|}{ Mother seroconverted to HR-HPV } \\
\hline No & Ref & & & & & \\
\hline Yes & 0.81 & $0.67-0.98$ & 0.039 & 0.84 & $0.69-1.03$ & 0.106 \\
\hline \multicolumn{7}{|l|}{ Mother seropositive to HR-HPV at baseline } \\
\hline Yes & Ref & & & & & \\
\hline No & 1.10 & $0.85-1.42$ & 0.463 & & & \\
\hline \multicolumn{7}{|l|}{ Baseline oral HR-HPV DNA status } \\
\hline HR-HPV- & Ref & & & & & \\
\hline HR-HPV+ & 0.80 & $0.54-1.19$ & 0.285 & & & \\
\hline \multicolumn{7}{|l|}{ Baseline PAP smear } \\
\hline ASCUS+ & Ref & & & & & \\
\hline Negative (WNL) & 1.76 & $0.76-4.10$ & 0.184 & & & \\
\hline \multicolumn{7}{|l|}{ Marital Status at baseline } \\
\hline Singe & Ref & & & & & \\
\hline Married & 1.19 & $0.77-1.81$ & 0.419 & & & \\
\hline Living with partner & 1.30 & $0.86-1.97$ & 0.208 & & & \\
\hline Divorced & 1.42 & $0.95-2.15$ & 0.086 & & & \\
\hline \multicolumn{7}{|l|}{ Employment status } \\
\hline Employed & Ref & & & & & \\
\hline Student & 0.82 & $0.61-1.10$ & 0.192 & & & \\
\hline Unemployed & 0.90 & $0.75-1.07$ & 0.257 & & & \\
\hline \multicolumn{7}{|l|}{ Age at onset of sexual activity } \\
\hline Below 13 years & Ref & & & & & \\
\hline Above 13 years & 1.15 & $1.05-1.27$ & 0.003 & 1.05 & $0.93-1.17$ & 0.394 \\
\hline \multicolumn{7}{|l|}{ No. of sexual partners until age of $20 \mathrm{yrs}$} \\
\hline 0-2 partners & Ref & & & & & \\
\hline 3-5 partners & 0.89 & $0.76-1.05$ & 0.201 & & & \\
\hline 6-10 partners & 1.05 & $0.92-1.19$ & 0.410 & & & \\
\hline$>10$ partners & 0.73 & $0.46-1.18$ & 0.206 & & & \\
\hline \multicolumn{7}{|l|}{ Life-time number of sexual partners } \\
\hline 1-2 partners & Ref & & & & & \\
\hline 3-5 partners & 1.12 & $1.02-1.24$ & 0.015 & 1.12 & $1.02-1.23$ & 0.011 \\
\hline 6-10 partners & 0.83 & $0.61-1.13$ & 0.246 & 0.85 & $0.62-1.16$ & 0.311 \\
\hline$>10$ partners & 0.81 & $0.63-1.04$ & 0.105 & 0.81 & $0.63-1.04$ & 0.104 \\
\hline \multicolumn{7}{|l|}{ No. of weekly intercourse } \\
\hline $0-1$ intercourse & Ref & & & & & \\
\hline 2-4 intercourses & NC & & & & & \\
\hline 5-10 intercourses & NC & & & & & \\
\hline$>10$ intercourses & NC & & & & & \\
\hline$>10$ vs. $0-1$ (only calculable) & 1.03 & $0.88-1.14$ & 0.961 & & & \\
\hline No. of deliveries in all partnerships (continuous var)* & 1.06 & $0.98-1.15$ & 0.107 & & & \\
\hline \multicolumn{7}{|l|}{ Practices of oral sex } \\
\hline No & Ref & & & & & \\
\hline Yes & 1.02 & $0.87-1.20$ & 0.739 & & & \\
\hline \multicolumn{7}{|l|}{ Practices of anal sex } \\
\hline No & Ref & & & & & \\
\hline Yes & 1.22 & $0.97-1.55$ & 0.087 & 1.16 & $0.83-1.62$ & 0.375 \\
\hline \multicolumn{7}{|l|}{ Initiation of OC usage } \\
\hline Above 20 years & Ref & & & & & \\
\hline
\end{tabular}


Table 1 Predictors of species 7 and 9-type specific incident ${ }^{\mathrm{a}}$ HPV infections $^{\mathrm{b}}$ (Continued)

\begin{tabular}{|c|c|c|c|c|c|c|}
\hline Below 20 years & 1.32 & $1.04-1.23$ & 0.004 & 1.13 & $1.02-1.26$ & 0.017 \\
\hline \multicolumn{7}{|l|}{ OC use $(\mathrm{Y} / \mathrm{N})$} \\
\hline Never use & Ref & & & & & \\
\hline Ever use & 1.01 & $0.74-1.37$ & 0.948 & & & \\
\hline \multicolumn{7}{|l|}{ Smoking habits } \\
\hline Never smoker & Ref & & & & & \\
\hline Ever smoker & 1.06 & $0.92-1.21$ & 0.384 & & & \\
\hline \multicolumn{7}{|l|}{ Initiation of smoking } \\
\hline \multicolumn{7}{|l|}{ 10-13 years of age } \\
\hline$>13$ years of age & 1.16 & $1.01-1.35$ & 0.028 & 1.11 & $0.95-1.31$ & 0.159 \\
\hline \multicolumn{7}{|l|}{ History of STD } \\
\hline Yes & Ref & & & & & \\
\hline No & 1.06 & $0.89-1.27$ & 0.505 & & & \\
\hline \multicolumn{7}{|l|}{ History of genital warts } \\
\hline No & Ref & & & & & \\
\hline Yes & 0.93 & $0.81-1.08$ & 0.372 & & & \\
\hline \multicolumn{7}{|l|}{ History of oral warts } \\
\hline Yes & Ref & & & & & \\
\hline No & 1.08 & $0.79-1.32$ & 0.823 & & & \\
\hline \multicolumn{7}{|l|}{ 2nd pregnancy during FU } \\
\hline No $2^{\text {nd }}$ pregnancy during FU & Ref & & & & & \\
\hline Yes, $2^{\text {nd }}$ pregnancy during FU & 0.29 & $0.16-0.55$ & 0.0001 & 0.32 & $0.17-0.61$ & 0.0001 \\
\hline \multicolumn{7}{|l|}{ Change in marital status during FU* } \\
\hline No & Ref & & & & & \\
\hline Yes; living with partner & 0.74 & $0.41-1.32$ & 0.315 & 0.78 & $0.48-1.28$ & 0.340 \\
\hline Yes, married & 1.04 & $0.89-1.22$ & 0.572 & 1.10 & $0.84-1.45$ & 0.474 \\
\hline Yes, divorced & 1.11 & $1.01-1.22$ & 0.019 & 1.16 & $0.97-1.40$ & 0.102 \\
\hline \multicolumn{7}{|l|}{ No. of current sexual partners* } \\
\hline No & Ref & & & & & \\
\hline 1 or more & 1.02 & $1.00-1.04$ & 0.027 & $* *$ & & \\
\hline
\end{tabular}

Species 7 HPV genotypes: 18,39,45,59,68,70,85; Species 9 HPV genotypes: 16,31,33,35,52,58,67; ${ }^{a}$ Count outcome (incident events/person time at risk), as defined by the first incident event in baseline HPV-negative women during the follow-up; ${ }^{b}$ Results obtained from panel Poisson regression for count outcomes (log-link), clustered by woman-ID, FU visits as time variable, and $95 \% \mathrm{Cl}$ calculated by robust variance estimation; @adjusted for age and all significant univariates in the model; *the variables that are from the FU questionnaire; NC; no convergence obtained (with any working correlation structure) WNL, within normal limits; **rejected because of collinearity

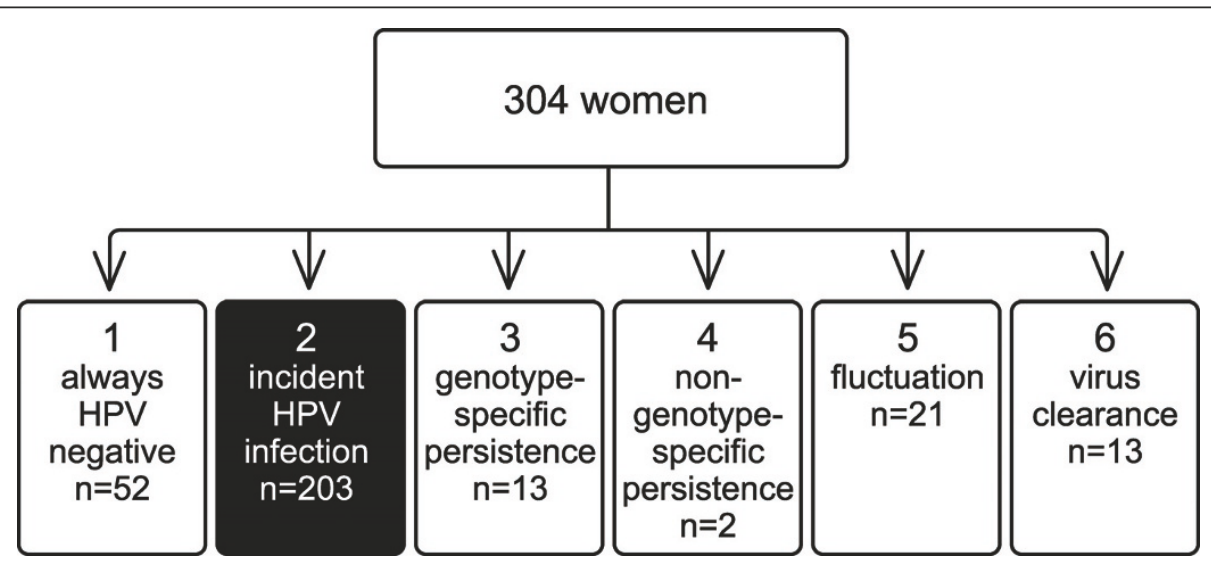

Figure 2 Outcome of the HPV infections during follow-up*. *The genotype-specific outcome of HPV infection in each woman was assessed by comparing the viral events at each FU visit to the baseline HPV status, and 6 different main outcomes were identified. This study evaluated the incidence of genotype-specific HPV infection, women in the second outcome. 
model [26,27]. FU visit was the time variable in the panel settings, and incident HPV-infection (count variable) as the dependent variable, with Poisson log-link function. The independent within-group correlation structure for PA model, with robust variance estimator (of 95\%CI) to account for within-subject correlation was the best-fitted covariance pattern, defined by QIC (quasi-likelihood information criterion [27]. With these options, Poisson regression for panel data is similar to PA GEE-model, both giving identical results.

In univariate Poisson, we first tested all covariates recorded at baseline questionnaire as well as some selected variables from the FU questionnaire (e.g. a new partner), previously implicated as potential risk factors of HPV in this cohort $[18,28]$. In the final multivariate model, only variables (as entities, not as sub-categories) that were significant (or borderline significant) in univariate Poisson were entered and were adjusted for age at study entry. All statistical tests were two-sided and declared significant at p-value $<0.05$ level.

\section{Results}

\section{Type-specific incident infections}

Of the 255 baseline HPV-negative mothers enrolled in the cohort, 203 experienced an incident event during the FU. The mean follow-up time of these 203 mothers was $58.6 \pm 25.2$ (SD) months (median 64.3; range 694.5). HPV16 caused most frequently incident infection $(47.8 \%, \mathrm{n}=97)$, followed by HPV18 (3.9\%, $\mathrm{n}=8)$, HPV70 (3.0\%, n = 6), HPV6 and HPV45 (both 2.5\%, $\mathrm{n}=$ $5)$. Multiple-type infections were the second most common incident events after HPV16, with 25.1\% ( $\mathrm{n}=51$ ) frequency. HPV16 and HPV18 were detected in 70.6\% $(\mathrm{n}=36)$ and $27.2 \%(\mathrm{n}=14)$ of the multiple-type infections, respectively.

The mean times to the first incident event are shown in Table 2. The longest actuarial mean time (75 months) was associated with a single case of HPV33. Of the types with more than one case, HPV31 and HPV45 had actuarial mean times of 34.5 months and 32.8 months, respectively, while the actuarial mean times of HPVtypes 6,16,18,35,56,58 varied between 21.5-29 months.

Apart from the single case of HPV33, HPV56 showed the second longest crude mean time of 42.4 months, followed by HPV16, 18 and 31, with 23.1, 20.6 and 20.1 months, respectively. Remaining genotypes had crude mean times between 6.3 and 17 months.

Species 9 was the most dominant species covering $54.7 \%(\mathrm{n}=111)$ of all incident infections and had actuarial mean time of 27.5 months (95\%CI23.3-31.7) and crude mean time of 22.6 months (95\%CI19.7-25.4). The second and third most common species were species 7 and species 10 , with $10.8 \%(n=22)$ and $3.9 \%$ $(\mathrm{n}=8)$ prevalence, respectively. Actuarial mean time for species 7, 9 and 10 was similar, 27.5, 27.5 and 27.0 months, respectively. Species 6 and 9 had the longest crude mean incidence times, 25.0 and 22.6 months, respectively.

The cumulative incidence of species 7 and 9 was compared with species 10 in univariate survival (KaplanMeier) analysis (Figure 3). Despite a lower cumulative incidence rate for species 10 (benign types), the difference was not statistically significant when compared to species 7 and 9 (log-rank test; $\mathrm{p}=0.892$ ).

\section{Incidence rates}

Of single genotypes, HPV16 had by far the highest actuarial IR, 15.6/1000 wmr (95\%CI12.5-18.6), followed by multiple-type infections, with $8.2 / 1000 \mathrm{wmr}(95 \%$ CI5.96-10.45). Actuarial IR for HPV18 was markedly lower, $1.3 / 1000 \mathrm{wmr}(95 \%$ CI0.39-2.17). Due to the dominant role of HPV16, species 9 showed the highest IR of 17.9/1000 wmr (95\%CI14.6-21.2), far exceeding that $(3.4 / 1000 \mathrm{wmr})$ of species 7 (Table 2).

The highest crude IR was ascribed to HPV70, accumulating incident events at a rate of $157.8 / 1000 \mathrm{wmr}$. This was followed by HPV73, HPV66, HPV82 and HPV52, with IRs of 133.3/1000 wmr, 133.1/1000 wmr, 107.1/1000 wmr and 107.1/1000 wmr, respectively. The crude IRs of HPV16 and HPV18 were far lower, and practically identical to each other, 43.3/1000 wmr and 43.4/1000 wmr, respectively. Due to this wide variation among individual types included in different species, the crude IRs between the HPV-species showed much less variation, i.e., from $40 / 1000 \mathrm{wmr}$ to $91 / 1000 \mathrm{wmr}$, when species 11 (HPV73 alone) is excluded (Table 2).

\section{Predictors of species-specific incident infections}

The predictors of genotype-specific incident infections of species 7 and 9 are shown in Table 1. In univariate Poisson regression, seven variables in total were significantly associated with incident infection. The following four variables were associated with increased risk: 1) mother being seroconverted to HR-HPV during FU, 2) $<13$ years of age at onset of sexual activity, 3) 1-2 lifetime sexual partners 4) $\geq 2$ sexual partners during FU. The other three variables were associated with a decreased risk of incident infection: 5) later initiation of oral contraceptives (OC)(age > 20 years), 6) age at initiation of smoking (age10-13 years) and 6) pregnancy at FU-visit.

When all significant and borderline significant variables were entered in the multivariate Poisson PA model, together with mother's age, three variables retained their significance as independent factors with lower risk for incident species 7 and 9 infection during the FU: 1$)>2$ life-time sexual partners $(\mathrm{p}=0.011), 2)$ late $(>20$ years) initiation of OCs $(p=0.017)$, and 3$)$ 
Table 2 Times to incident infections and incidence rates for different HPV genotypes and species $^{\mathrm{a}}$

\begin{tabular}{|c|c|c|c|c|c|c|}
\hline \multirow[b]{2}{*}{ HPV Genotype: } & \multicolumn{2}{|c|}{$\begin{array}{l}\text { Incident } \\
\text { Infections }\end{array}$} & \multicolumn{2}{|c|}{$\begin{array}{l}\text { Mean Time to } 1^{\text {st }} \text { Incident Infection } \\
\text { (months) }\end{array}$} & \multicolumn{2}{|c|}{$\begin{array}{l}\text { Incident Rate (IR) per 1,000 women months at } \\
\text { risk (wmr) }\end{array}$} \\
\hline & $\mathrm{N}$ & $\%$ & Actuarial $^{\mathrm{b}}(95 \% \mathrm{Cl})$ & Crude $^{c}(95 \% \mathrm{Cl})$ & Actuarial $^{\mathrm{b}}(95 \% \mathrm{Cl})$ & Crude $^{c}(95 \% \mathrm{Cl})$ \\
\hline$\overline{\mathrm{HPV} 6}$ & 5 & 2.5 & $27.2(9.2-45.2)$ & $15.2(10.1-20.2)$ & $0.8(0.09-1.51)$ & $65.9(10.0-121.5)$ \\
\hline HPV11 & 2 & 1.0 & $12.8(12.2-13.4)$ & $12.8(12.2-13.4)$ & $0.3(0.01-0.76)$ & $78.2(2.5-179.3)$ \\
\hline HPV16 & 97 & 47.8 & $25.2(22.0-28.3)$ & $23.1(20.2-26.0)$ & $15.6(12.5-18.6)$ & $43.3(34.8-51.7)$ \\
\hline HPV18 & 8 & 3.9 & $27.1(13.8-40.3)$ & $20.5(14.2-26.8)$ & $1.3(0.39-2.17)$ & $48.7(15.8-81.7)$ \\
\hline HPV31 & 4 & 2.0 & $34.5(7.4-61.6)$ & $20.1(6.1-34.1)$ & $0.6(0.01-1.27)$ & $49.8(22.4-97.7)$ \\
\hline HPV33 & 1 & 0.5 & $75.0(75.0-75.0)$ & $75.0(75.0-75.0)$ & $0.2(0.01-0.47)$ & $13.3(1.3-39.3)$ \\
\hline HPV35 & 2 & 1.0 & $21.5(7.7-35.3)$ & $12.9(11.7-14.1)$ & $0.3(0.01-0.76)$ & 76.9 (25.5-179.3) \\
\hline HPV44 & 1 & 0.5 & $12.5(12.5-12.5)$ & $12.5(12.5-12.5)$ & $0.2(0.01-0.47)$ & $80.0(6.8-221.8)$ \\
\hline HPV45 & 5 & 2.5 & $32.8(13.9-51.6)$ & $13.7(6.7-20.6)$ & $0.8(0.09-1.51)$ & $72.4(11.2-133.6)$ \\
\hline HPV51 & 2 & 1.0 & $13.4(0-35.7)$ & $13.4(0-35.7)$ & $0.3(0.01-0.76)$ & $74.1(24.7-172.8)$ \\
\hline HPV52 & 3 & 1.5 & $9.4(2.0-16.8)$ & $9.4(2.0-16.8)$ & $0.5(0.06-1.02)$ & $107.1(7.4-221.7)$ \\
\hline HPV56 & 2 & 1.0 & $25.4(7.7-43.1)$ & $42.4(0-101.0)$ & $0.3(0.01-0.76)$ & $23.5(8.6-55.7)$ \\
\hline HPV58 & 4 & 2.0 & $29.0(1.0-57.0)$ & $13.5(4.1-22.8)$ & $0.6(0.01-1.27)$ & $74.1(42.2-143.9)$ \\
\hline HPV59 & 3 & 1.5 & $17.0(2.0-32.1)$ & $17.0(1.9-32.1)$ & $0.5(0.06-1.02)$ & $58.8(5.8-123.4)$ \\
\hline HPV66 & 2 & 1.0 & $7.6(0-17.8)$ & $7.6(0-17.8)$ & $0.3(0.01-0.76)$ & $133.1(38.2-305.0)$ \\
\hline HPV70 & 6 & 3.0 & $11.2(2.9-19.4)$ & $6.3(2.0-10.6)$ & $1.0(0.19-1.73)$ & $157.8(41.9-273.8)$ \\
\hline HPV73 & 2 & 1.0 & $7.6(0-18.4)$ & $7.6(0-18.4)$ & $0.3(0.01-0.76)$ & $133.3(38.7-305.3)$ \\
\hline HPV82 & 3 & 1.5 & $9.4(2.3-16.6)$ & $9.4(2.3-16.6)$ & $0.5(0.06-1.02)$ & $107.1(74.1-221.7)$ \\
\hline Multiple types & 51 & 25.1 & $32.1(26.2-37.9)$ & $19.8(16.4-23.2)$ & $8.2(5.96-10.45)$ & $50.5(36.9-63.9)$ \\
\hline \multicolumn{7}{|l|}{ HPV Species: } \\
\hline Species $5(26,51,69,82)$ & 5 & 2.5 & $11.0(2.7-19.3)$ & $11.0(2.7-19.3)$ & $0.8(0.09-1.51)$ & $90.9(14.9-166.9)$ \\
\hline Species $6(30,53,56,66)$ & 4 & 2.0 & $16.5(3.5-29.4)$ & $25.0(0-56.3)$ & $0.6(0.01-1.27)$ & $40.0(1.6-78.4)$ \\
\hline Species $7(18,39,45,59,68,70,85)$ & 22 & 10.8 & $27.5(17.3-37.7)$ & 14.6(10.5-18.7) & $3.5(2.1-5.0)$ & $68.5(40.9-96.2)$ \\
\hline Species $9(16,31,33,35,52,58,67)$ & 111 & 54.7 & $27.5(23.3-31.7)$ & $22.6(19.7-25.4)$ & $17.9(14.6-21.2)$ & $44.3(36.3-52.4)$ \\
\hline Species $10(6,11,13,44,55,74)$ & 8 & 3.9 & $27.0(11.0-42.9)$ & $14.2(11.2-17.4)$ & $1.3(0.39-2.17)$ & $70.2(23.3-117.0)$ \\
\hline Species $11(34,73)$ & 2 & 1.0 & $7.6(0-18.4)$ & $7.6(0-18.4)$ & $0.3(0.01-0.76)$ & $133.3(38.7-305.3)$ \\
\hline
\end{tabular}

${ }^{a}$ among the 203 women of the Finnish Family HPV study who had an incident infection during the FU; ${ }^{b}$ all baseline HPV-negative women at risk, months at risk calculated 1) until the first incident event, or 2) as total FU months for those with no incident event (Total wmr $=6,212$ ); ${ }^{c}$ only women with an incident event (months at risk calculated until the first incident event);

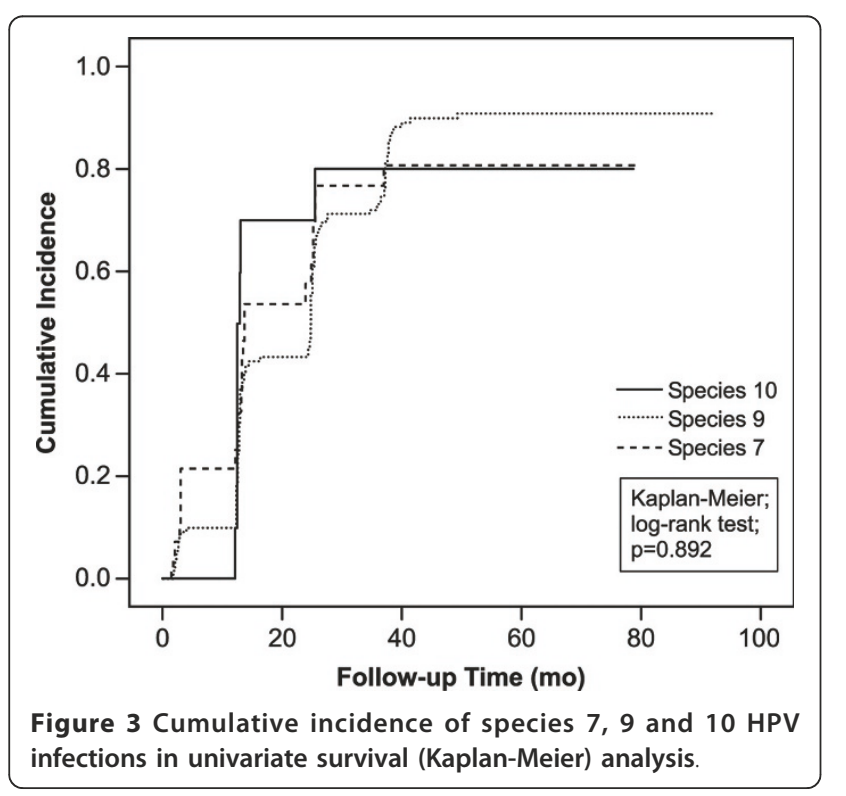

pregnancy at FU-visit $(\mathrm{p}=0,0001)$, with the details of estimates in sub-categories shown in Table 1.

\section{Discussion}

This is one of the first studies to assess type-specific incident HPV-infection [8-16], in contrast to the previous studies, where acquisition of HPV-infection has been analysed collectively for all HPV-types or acquisition of HR- and LR-types has been compared [4-7]. Similarly, in currently available literature, it is hard to find the times to the first incidence infections at the genotype-level, most reports being focused on duration of incident infections $[8,9,16]$.

We previously analysed crude incidence times collectively for 13 HR-HPV-types detected by Hybrid capture 2-assay [6]. It took an average of 16.6 months to develop the first incident HR-HPV event. In the present study, we went further and provide these times for individual HPV-genotypes (and species) both as actuarial and crude format. To calculate the former, included are also 
baseline HPV-negative women who never develop an incident event, while the latter is calculated only for women who develop incident events. Thus, the actuarial times reflect the real-life situation, while indicating how long it takes in a cohort of baseline HPV-negative women to develop the first incident infections. On the other hand, the crude times indicate the time that these first incident infections take to develop among women who all experience an incident event. These crude (typespecific) incidence times provide a robust measure to compare different HPV-genotypes in their speed to develop the first incident events (Table 2). In this respect, individual genotypes showed marked differences in their crude incidence times, varying within the range of 2 to 90 months, with the mean of 20.3 and median of 13.5 months (data not shown). Generally speaking, LRHPV-types had shorter crude mean incidence times than HR-HPV-genotypes. However, despite the significant overall difference $(p=0.0001)$ between the individual genotypes, these results are hampered by multiple comparisons and a small number of cases in each strata. Of interest is the observation that no significant differences were observed between mean incidence times of HPV16, HPV18 and multiple-type infections, each being represented by sufficient number of cases.

As evident in Figure 3, these incident events show a tendency for clustering around the time points of the control visits, i.e., at 2-, 12-, 24-, 36- months and 6 years. This flaw is inherent to the study design, however, and equally affects all studies with similar design, i.e., HPV sampling at irregular (and relatively long) intervals. Because of the fact that the incident events rarely (if ever) occur exactly at the time point of sampling, but somewhere in between the two subsequent samplings, and because the event leads to censoring of the subject (= no longer at risk for incident event), we can speak about interval censoring. Due to the fact that there are both "left-censored and right-censored" (relative to the point) data that occur at random, we feel that this should not cause a major bias, however. Of course, the exact times can only be obtained by very short ( 1 to 3 months) sampling times, which in the case of HPV (having protracted clinical course) are not feasible in practice.

Also the IR can be calculated as actuarial and crude, as done here. These two IRs are markedly different, because of the significantly different person months at risk. This also makes comparison between individual studies difficult, particularly when the FU-times and cohort size are substantially different. If one compares a setting where 1000 women are followed-up for 10 months (10.000 wmr), and another one with 100 women followed-up for 100 months $(10.000 \mathrm{wmr})$, certainly the IRs in the latter are higher. This is because the median incidence time is around 12-13 months and only a fraction of events can be detected with a short FU-time. In addition, it is essential to know the age-profile of the cohort, because IR for HPV infection is critically age-dependent [7].

In our cohort, actuarial IR was by far the highest for HPV16, 15.6/1000 wmr. This is consistent with other studies, where HPV16 had the highest actuarial IR, albeit the absolute IRs of these cohorts was much lower. A young women's health study-cohort from USA reported an actuarial IR of 5.9/1000 wmr for HPV16 [9]. In the Ludwig-McGill low-income cohort, the actuarial IR for HPV16 was $1.4 / 1000 \mathrm{wmr}$ [8], which is very similar to another cohort consisting of sexually active women from Hawaii, 1.77/1000 wmr [16]. Due to the dominant role of HPV16, also the actuarial IR of species 9 was the highest $17.9 / 1000 \mathrm{wmr}$, which is three times higher than recently published by Goodman and co-workers. (5.4/1000 wmr) [16]. As pointed out above, these differences are explained by different cohort sizes and particularly by much shorter FU-times of the other studies, 10-15 months only $[8,9,16]$. Another factor is the different age-profile; the mean age of our cohort was 25.5 years which is close to 24.2 years in the study by Giuliano and co-workers [9] where as the mean age in the study by Goodman and co-workers was 35 years [16]. The IRs are higher in our cohort and Giuliano cohort [9] than in studies on older women $[8,16]$, which gives further support to close age-dependence [6,7].

This is one of the first studies on crude IRs, which reflect the differences in the rates at which individual genotypes accumulate incident events among women who have these events. Although firm conclusions on single genotypes are difficult because of the rarity of many individual genotypes, it is interesting to note that the crude IR of the key LR-HPV-types (HPV6,11), is almost twice as high as that of the two main HR-types (HPV16,18). This indicates that the former develop incident infections at much higher rate, which is also shown by their significantly shorter times to incident events (Table 2). Using rate-ratio (RR) statistics, one cannot detect significant differences between the different HPV-species in their crude IRs (data not shown). Much larger cohort is needed to establish whether such differences exist between individual HR-HPV-genotypes. If confirmed, however, such data would have important implications e.g. in the selection of the most aggressive genotypes with high IRs as targets of the primary prevention.

As to the risk-factors for incident species 7/9 infections, seven variables were significant predictors in univariate analysis. First of these was linked with HPV-serology [25]; mothers who failed to seroconvert to HR-HPV during the FU were at increased risk for incident infections (Table 1). It is well established that serological response to HPVinfections needs several months to become detectable $[25,29]$. Thus, women who experience an incident event close to the end of FU have not enough time to become 
seroconverted during the observation period. There is some evidence that seroconversion may fail with transient and even with some persistent infections [30]. It is commonly believed that high levels of HPV-antibodies detected after seroconversion will protect against a new infection. Thus, seroconversion detected during the early months of FU could implicate an incident event that took place before the baseline visit, and these high antibody levels, except for being incompatible with new incident events, might also neutralise the virus and make these women baseline HPV DNA-negative.

Initiation of smoking beyond 13 years of age was associated with an increased risk of incident HPV-infection, but lost its significance in multivariate model. Some studies have found no association between smoking and incident infection $[10,16]$, whereas others indicating current smoking to increase the risk $[5,11,13,15]$. Our recent analysis disclosed that initiation of smoking at $<13$ years of age increased the risk of type-specific persistence [31]. Because incident infections precede viral persistence, the present data are consistent with this observation, implicating that women who start smoking later have had less time to develop persistent infection, and consequently, are at the phase when incident infections accumulate.

Women who started their sexual activity before 13 years of age were found to have a lower risk for incident infections during the FU. Also this association is in line with our recent analysis disclosing early age of sexual debut as a risk factor for HR-HPV persistence [31]. It is likely that women with later onset are at increased risk for incident infections, just because those with longer sexual exposure have already experienced infection, and either cleared or developed a persistent infection by the time they reach their 20s (mean age of this study cohort being 25.5 years).

The same analogy applies to life-time number of sexual partners (also a proxy to HPV exposure), shown in this study to be inversely related to the risk of incident infections, i.e., lower partner number was associated with an increased risk. It seems likely that those with more partners have already experienced such an event before enrolled in the study, i.e., are baseline HPV+ and by definition, no longer at risk for incident infection by the same HPV genotype.

The initiation of OC usage before the age of 20 increased the risk for incident infection and was a significant predictor also in the multivariate model. Previous studies report conflicting results; current use of OCs has been shown to increase [11] or decrease [4] the risk of incident infection. In addition, it has been reported that the current users of OCs were not in increased risk and that the past users of OCs seemed to be protected, as shown by a decrease of incident infections with the years of $\mathrm{OC}$ use [16]. Contradictory to the previous finding, a recent study stated that the risk for incident infection increased with increasing years of OC use [13]. It is obvious that further studies are needed to evaluate the association of $\mathrm{OC}$ with incident infections.

Another significant protective predictor was the second pregnancy during the FU (Table 1). No previous data are available from a similar setting where newly delivered mothers were prospectively followed-up. We have recently shown that women committed to the second child did not share many of the known life-style behavioural risk factors of HPV-infection [32], and this could be the likely explanation for this significant (IRR $=0.32,95 \%$ CI0.17-0.61) protective effect of a new pregnancy against incident species 7/9 HPV-infections in the present analysis. Some recent data suggest that parity was protective especially against LR-HPV-types [10]. In our cohort, increasing parity did not show any such effect. However, in a large screening study (the NIS Cohort), ever being pregnant was an independent predictor of incident infection [6].

The main limitations of this current study are firstly the small cohort size of the women; the total number of incidence infections was 203. To gain more information on genotype specific incident HPV-infections, times and rates, and to increase the statistical power, a much larger cohort is needed. Secondly the women were all pregnant at the time of enrolling to this study, as it is the special strength of this study it also may be considered as a limitation because the detailed mechanism how pregnancy and HPV infections interacts are not that well understood.

\section{Conclusions}

Data obtained from this study indicate that the probability of mothers, who test HPV-negative just before delivery, to contract an incident infection by species 7/9. genotypes during the subsequent follow-up is less likely among those who report more than 2 life-time sexual partners at baseline, start using of OCs after age 20, and become pregnant for the second time during the followup. To the best of our knowledge, this is the first study where actuarial and crude times to the incident events as well as actuarial and crude IRs are evaluated the genotype- and HPV-species level. Obtaining genotype-specific data during long-term follow-up is needed for better understanding of the natural history of genotype specific $\mathrm{HPV}$-infections, e.g. the times and rates at which each genotype accumulates incident events. It sounds feasible to reason that in the future, those genotypes with shortest times to incident infections (i.e., the highest IRs), could be the most appropriate targets for early prevention, e.g. by genotype-specific multivalent HPV vaccines.

\section{Acknowledgements}

The skilful technical assistance of Mrs. Tatjana Peskova, Mariia Henttinen and Ketlin Adel is gratefully acknowledged. This study has been supported in 
part by the National Graduate School of Clinical Investigation (CLIGS), Academy of Finland, Finnish Cancer Foundation as well as by the Government Special Foundation (EVO) to Turku University Hospital.

\section{Author details}

${ }^{1}$ Medicity Research Laboratory and Department of Oral Pathology, Institute of Dentistry, Faculty of Medicine, University of Turku, Lemminkäisenkatu 2, 20520 Turku, Finland. ${ }^{2}$ Department of Obstetrics and Gynecology, Turku University Hospital, University of Turku, Kiinanmyllynkatu 4-8, 20521 Turku, Finland. ${ }^{3}$ Department of Oncology and Radiotherapy, Turku University Hospital, Hämeentie 11, 20500 Turku, Finland.

\section{Authors' contributions}

$\mathrm{KL}$ is the first author in this study, participated in execution of the work at all phases, this study is part of her PhD project. KS is a pathologist and senior author in the project, with main responsibility in maintaining the databank as well as designing and running the statistical analyses. SG is the clinical principal investigator and coordinator at the Department of Obstetrics and Gynecology, and has participated in the design of the study and analysis and writing of the results. MR has been responsible for enrolment and examination of all mothers during the follow-up and writing of the results. SS is the coordinator and principal investigator of the Finnish Family HPV study and the head of the HPV research laboratory. All authors have read and approved the final version of this manuscript.

\section{Competing interests}

The authors declare that they have no competing interests.

Received: 7 May 2010 Accepted: 22 June 2011 Published: 22 June 2011

\section{References}

1. De Villiers EM: Classification of papillomaviruses. Virology 2004, 324:17-27.

2. Muñoz N, Bosch FX, de Sanjosé S, Herrero R, Castellsagué X, Shah KV, Snijders PJ, Meijer CJ, International Agency for Research on Cancer Multicenter Cervical Cancer Study Group: Epidemiologic classification of human papillomavirus types associated with cervical cancer. $N$ Engl J Med 2003, 348:518-27.

3. Bosch FX, Burchell AN, Schiffman M, Giuliano AR, de Sanjose S, Bruni L, Tortolero-Luna G, Kjaer SK, Muñoz N: Epidemiology and natural history of human papillomavirus infections and type-specific implications in cervical neoplasia. Vaccine 2008, 26:K1-16.

4. Moscicki AB, Hills N, Shiboski S, Powell K, Jay N, Hanson E, Miller S, Clayton L, Farhat S, Broering J, Darragh T, Palefsky J: Risks for incident human papillomavirus infection and low-grade squamous intraepithelial lesion development in young females. JAMA 2001, 285:2995-3002.

5. Sellors JW, Karwalajtys TL, Kaczorowski J, Mahony JB, Lytwyn A, Chong S, Sparrow J, Lorincz A, Survey of HPV in Ontario Women Group: Incidence, clearance and predictors of human papillomavirus infection in women. CMAJ 2003, 168:421-5.

6. Syriänen S, Shabalova I, Petrovichev N, Kozachenko V, Zakharova T, Pajanidi J, Podistov J, Chemeris G, Sozaeva L, Lipova E, Tsidaeva I, Ivanchenko O, Pshepurko A, Zakharenko S, Nerovjna R, Kljukina L, Erokhina O, Branovskaja M, Nikitina M, Grunberga V, Grunberg A, Juschenko A, Tosi P, Cintorino M, Santopietro R, Syrjänen K: Acquisition of high-risk human papillomavirus infections and pap smear abnormalities among women in the New Independent States of the Former Soviet Union. J Clin Microbiol 2004, 42:505-11.

7. Syrjänen S, Shabalova I, Petrovichev N, Podistov J, Ivanchenko O, Zakharenko S, Nerovjna R, Kljukina L, Branovskaja M, Juschenko A, Tosi P, Syrjänen K, NIS Cohort Study Group: Age-specific incidence and clearance of high-risk human papillomavirus infections in women in the former Soviet Union. Int J STD AIDS 2005, 16:217-23.

8. Franco EL, Villa LL, Sobrinho JP, Prado JM, Rousseau MC, Désy M, Rohan TE: Epidemiology of acquisition and clearance of cervical human papillomavirus infection in women from a high-risk area for cervical cancer. J Infect Dis 1999, 180:1415-23.

9. Giuliano AR, Harris R, Sedjo RL, Baldwin S, Roe D, Papenfuss MR, Abrahamsen M, Inserra P, Olvera S, Hatch K: Incidence, prevalence, and clearance of type-specific human papillomavirus infections: The Young Women's Health Study. J Infect Dis 2002, 186:462-9.
10. Muñoz N, Méndez F, Posso H, Molano M, van den Brule AJ, Ronderos M, Meijer C, Muñoz A, Instituto Nacional de Cancerologia HPV Study Group: Incidence, duration, and determinants of cervical human papillomavirus infection in a cohort of Colombian women with normal cytological results. J Infect Dis 2004, 190:2077-87.

11. Winer RL, Lee SK, Hughes JP, Adam DE, Kiviat NB, Koutsky LA: Genital human papillomavirus infection: incidence and risk factors in a cohort of female university students. Am J Epidemiol 2003, 157:218-26.

12. Chao A, Chang CJ, Lai CH, Chao FY, Hsu YH, Chou HH, Huang HJ, Jung SM, Lin CT, Cheng HH, Huang CC, Yang JE, Chang TC: Incidence and outcome of acquisition of human papillomavirus infection in women with normal cytology-a population-based cohort study from Taiwan. Int I Cancer 2010, 126:191-8.

13. Nielsen A, Iftner T, Munk C, Kjaer SK: Acquisition of high-risk human papillomavirus infection in a population-based cohort of Danish women. Sex Transm Dis 2009, 36:609-15.

14. Fukuchi E, Sawaya GF, Chirenje M, Magure T, Tuveson J, Ma Y, Shiboski S, Da Costa M, Palefsky J, Moscicki AB, Makunike-Mutasa R, Chipato T, SmithMcCune KK: Cervical human papillomavirus incidence and persistence in a cohort of HIV-negative women in Zimbabwe. Sex Transm Dis 2009, 36:305-11

15. Oh JK, Ju YH, Franceschi S, Quint W, Shin HR: Acquisition of new infection and clearance of type-specific human papillomavirus infections in female students in Busan, South Korea: a follow-up study. BMC Infect Dis 2008, 8:13.

16. Goodman MT, Shvetsov YB, McDuffie K, Wilkens LR, Zhu X, Thompson PJ, Ning L, Killeen J, Kamemoto L, Hernandez BY: Prevalence, acquisition, and clearance of cervical human papillomavirus infection among women with normal cytology: Hawaii Human Papillomavirus Cohort Study. Cancer Res 2008, 68:8813-24.

17. Richardson $H$, Kelsall $G$, Tellier P, Voyer $H$, Abrahamowicz M, Ferenczy A, Coutlée F, Franco EL: The natural history of type-specific human papillomavirus infections in female university students. Cancer Epidemiol Biomarkers Prev 2003, 12:485-90

18. Rintala MA, Grénman SE, Puranen MH, Isolauri E, Ekblad U, Kero PO, Syrjänen SM: Transmission of high risk HPV between parents and infants: a prospective HPV Family Study in Finland. J Clin Microbiol 2005, 43:376-81.

19. Rintala MA, Grénman SE, Järvenkylä ME, Syrjänen KJ, Syrjänen SM: High-risk types of human papillomavirus (HPV) DNA in oral and genital mucosa of infants during their first 3 years of life: experience from the Finnish HPV Family Study. Clin Infect Dis 2005, 41:1728-33.

20. Louvanto K, Syrjänen K, Rintala MA, Grénman SE, Syrjänen SM: Genotypespecific clearance of genital human papillomavirus (HPV) infections among mothers in the Finnish family HPV study. J Clin Microbiol 2010 48:2665-71.

21. Schmitt M, Bravo IG, Snijders PJ, Gissmann L, Pawlita M, Waterboer T: Beadbased multiplex genotyping of human papillomaviruses. J Clin Microbiol 2006, 44:504-12.

22. Snijders PJF, van den Brule AJC, Schrijnemakers HFJ, Snow G, Meijer CJLM Walboomers JMM: The use of general primers in the polymerase chain reaction permits the detection of a broad spectrum of human papillomavirus genotypes. J Gen Virol 1990, 71:173-181.

23. Miller SA, Dykes DD, Polesky HF: A simple salting out procedure for extracting DNA from human nucleated cells. Nucleic Acids Res 1988, 16:1215.

24. Anttila M, Syrjänen S, Ji H, Saarikoski S, Syrjänen K: Failure to demonstrate human papillomavirus DNA in epithelial ovarian cancer by general primer PCR. Gynecol Oncol 1999, 72:337-341.

25. Syrjänen $S$, Waterboer T, Sarkola M, Michael K, Rintala M, Syrjänen $K$, Grenman S, Pawlita M: Dynamics of human papillomavirus serology in women followed up for 36 months after pregnancy. J Gen Virol 2009, 90:1515-26.

26. Diggle PJ, Liang KY, Zeger SL: Analysis of longitudinal data. 1 edition. Oxford: Oxford University Press: 1994.

27. Hardin J, Hilbe JM: Generalized estimating equations Boca Raton, FL: Chapman \& Hall; 2003.

28. Kulmala SM, Shabalova IP, Petrovitchev N, Syrjänen KJ, Gyllensten UB, Johansson BC, Syrjänen SM, New Independent States of the former Soviet Union Cohort Study Group: Type-specific persistence of high-risk human papillomavirus infections in the New Independent States of the former 
Soviet Union Cohort Study. Cancer Epidemiol Biomarkers Prev 2007,

16:17-22.

29. Ho GY, Studentsov YY, Bierman R, Burk RD: Natural history of human papillomavirus type 16 virus-like particle antibodies in young women. Cancer Epidemiol Biomarkers Prev 2004, 13(1):110-6.

30. Carter JJ, Koutsky LA, Hughes JP, Lee SK, Kuypers J, Kiviat N, Galloway DA: Comparison of human papillomavirus types 16, 18, and 6 capsid antibody responses following incident infection. J Infect Dis 2000, 181(6):1911-9.

31. Louvanto K, Rintala M, Syrjänen K, Grenman S, Syrjänen S: Genotypespecific persistence of genital human papillomavirus (HPV) infections in women followed for 6 years in the Finnish Family HPV Study. J Infect Dis 2010, 202:436-44.

32. Sarkola ME, Grenman SE, Rintala MA, Syrjanen KJ, Syrjanen SM: Effect of second pregnancy on maternal carriage and outcome of high-risk human papillomavirus (HPV): experience from the prospective finnish family HPV study. Gynecol Obstet Invest 2009, 67:208-216.

\section{Pre-publication history}

The pre-publication history for this paper can be accessed here:

http://www.biomedcentral.com/1471-2334/11/179/prepub

doi:10.1186/1471-2334-11-179

Cite this article as: Louvanto et al:: Incident cervical infections with high- and low-risk human papillomavirus (HPV) infections among mothers in the prospective Finnish Family HPV Study. BMC Infectious Diseases 2011 11:179.

\section{Submit your next manuscript to BioMed Central and take full advantage of:}

- Convenient online submission

- Thorough peer review

- No space constraints or color figure charges

- Immediate publication on acceptance

- Inclusion in PubMed, CAS, Scopus and Google Scholar

- Research which is freely available for redistribution

Submit your manuscript at www.biomedcentral.com/submit 